\title{
Research Paper: Alternative Medicine' Complaints Lodged to the Tehran Forensic Medicine Organization From 2011 to 2017
}

\author{
Mohammad Ali Emam Hadi ${ }^{1}$ Q, Baharak Sabet Divshaly ${ }^{1}$ Q, Farahnaz Azimy², Babak Sabet Divshaly ${ }^{3}$ \\ 1. Department Forensic Medicine, School of Medicine, Shahid Beheshti University of Medical Sciences, Tehran,Iran. \\ 2. Department of Autopsy, Legal Medicine Organization, Tehran, Iran. \\ 3. Department of Surgery, School of Medicine, Shahid Beheshti University of Medical Sciences, Tehran, Iran.
}

\begin{tabular}{|l|l|}
$\begin{array}{l}\text { Use your device to scan } \\
\text { and read the article online }\end{array}$ \\
Citation: Emam Hadi MA, Sabet Divshaly B, Azimy F, Sabet Divshaly B. Alternative Medicine' Complaints Lodged to the \\
Tehran Forensic Medicine Organization From 2011 to 2017. International Journal of Medical Toxicology and Forensic Medi- \\
cine. 2020; 10(2):26707. https://doi.org/10.32598/ijmtfm.v10i2.26707 \\
dof/https://doi.org/10.32598/ijmtfm.v10i2.26707
\end{tabular}

\section{8}

Article info:

Received: 11 Aug 2019

First Revision: 20 Aug 2019

Accepted: 09 Oct 2019

Published: 20 Jun 2020

\section{A B STRACT}

Background: Complementary and alternative medicine is a non-conventional therapy and includes a wide range of medical treatments in different countries. This study was done to evaluate alternative medicine complaints lodged to the Tehran Forensic Medicine Organization from 2011-2017.

Methods: In this cross-sectional study, all documented complaints of complementary medicine lodged to the Tehran Forensic Medicine Organization from 2011-2017 were reviewed and assessed with retrospective follow-up. The inclusion criterion was complaints from complementary and alternative medicine, and the exclusion criterion was incomplete data. The study data included patients' demographic data, the therapist, the specialty of the therapist, type of disease, treatment method, adverse effects, the initial and final decision by the commission, and the amount of medical error. This information was extracted from the existing documents and recoded in the checklists.

Results: Medical errors were found in $53.4 \%$ of the complaints examined. The most common cause of complaint $(63 \%)$ was the adverse effects, of which the most common ones were phytotherapy (45.2\%) and cupping (Hijama) $(20.5 \%)$. The error was significantly different between physician and non-physician healers $(\mathrm{P}=0.001)$.

Conclusion: Based on this study, among the alternative medicine complaints lodged to the Tehran Forensic Medicine Organization from 2011-2017, the adverse effects were the main problem of complementary therapies confirmed in more than half of the complaints.

* Corresponding Author:

Baharak Sabet Divshaly, PhD.

Address: Department Forensic Medicine, School of Medicine, Shahid Beheshti University of Medical Sciences,Tehran,Iran.

Tel: +98 (912) 7343050

E-mail:dr.sabet100@gmail.com 


\section{Introduction}

omplementary or alternative medicine is a non-conventional medical therapeu-

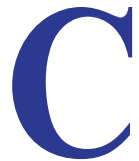
tic modality. This medicine includes a variety of treatments, including aromatherapy, phototherapy, acupuncture, and traditional medicine all around the world According to some Iranian studies, alternative medicine is used by up to $50 \%$ of the patients $[1,2]$. The World Health Organization has approved traditional and complementary medicine with different principles and has encouraged the use of this method in classic aspects. Unfortunately, there are multiple ethical and legal debates in this regard, especially when non-specialist subjects lack proper instructions for the assessment of traditional and complementary medicine $[3,4]$

The medical forensic organization should develop assessment tools for legal agencies to determine the medical errors and faults and their punishment in different medical fields [5]. The assessment in this era should be done in specialized commissions. Then the relevant reports about related complaints in this field would lead to the preparation of some guidelines and protocols [6]. This study was carried out to determine the alternative medicine charges reported to the Tehran Forensic Medicine Organization from 2011-2017.

\section{Materials and Methods}

In this cross-sectional study, all documented complaints of complementary and alternative medicine lodged to the Tehran Forensic Medicine Organization from 2011-2017 were examined and assessed with retrospective follow-up. The inclusion criterion was complaints from complemen- tary and alternative medicine, and the exclusion criterion was incomplete data. The study data included patients' demographic data, the therapist, the specialty of the therapist, type of disease, treatment method, adverse effects, the commission's initial and final decisions, and the amount of medical error. This information was extracted from the existing documents and recoded in the checklists.

The costs, according to USA dollars, were estimated, and changes were made according to Iran Central Bank declaims in each year. The obtained data were analyzed in SPSS V. 21.0, and the significance level was considered 0.05 .

\section{Results}

From 2011-2017, about 73 complaints were lodged from complementary medicine. The complainants were $50.7 \%$ male and $49.3 \%$, female with a Mean \pm SD age of $39.3 \pm 12.5$ years. The complaints were usually (63\%) for adverse effects. In more than half of the cases (53.4\%), the error was confirmed. The therapists were male and female in $87.7 \%$ and $12.3 \%$, respectively, with a Mean \pm SD age of $44 \pm 13$ years. Table 1 presents their demographic data. The most common age group was 40-60 years. Type of field was general and specialist physicians (except traditional specialist) $(35.61 \%)$ and then the ittars $(34.2 \%)$ and finally the traditional healers $(19.17 \%)$, including homeotherapist, massager, beekeeper, etc. (Figure 1).

The involved diseases and problems were mostly musculoskeletal, obesity, and internal medicine, with rates of $31.5 \%$, $16.4 \%$, and $13.7 \%$, respectively (Figure 2 ). The other less common diseases included weakness, addiction, varicose veins, and peripheral nervous system disorders. Herbal medicine and cupping (Hijama) were the most common treatments with rates of $45.2 \%$ and $20.5 \%$, respectively (Figure 3 ).

Table 1. Frequency distribution of age among patients and healer subjects

\begin{tabular}{ccc}
\hline & & No. (\%) \\
\hline Age (y) & Patients & Therapists \\
\hline$<12$ & $5(6.8)$ & $0(0)$ \\
\hline $12-20$ & $6(8.2)$ & $0(0)$ \\
\hline $20-40$ & $27(37)$ & $22(30.1)$ \\
$40-60$ & $30(41.1)$ & $46(63)$ \\
\hline 70 & $5(6.8)$ & $5(6.8)$ \\
\hline Total & $73(100)$ & 73 (100) \\
\hline
\end{tabular}




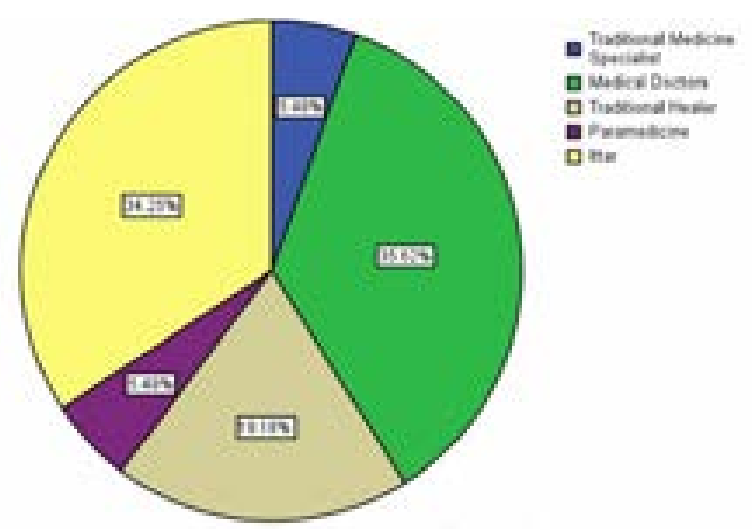

Figure 1. Field of activity among healers

Working years were averagely $10.4 \pm 6.7$ years. Cause of complaint differed according to the age of therapists $(\mathrm{P}<0.05)$, and in lower ages, higher adverse effects were seen. Also, working years were related to error establishment $(\mathrm{P}<0.05)$. The error was approved in $53.4 \%$, and total punishment costs were $\$ 31800000$ ranging from $\$ 55.5$ to $\$ 444.5$ in different documents. When the error of the physicians and legal punishments for non-physicians were considered as the outcome, there was a statistically significant association between the career of the healers and being punished with also substantial effects on the money considered as parallel as the $\operatorname{cost}(\mathrm{P}<0.05)$.

\section{Discussion}

The medical error was confirmed in $53.4 \%$ of the complaints examined. The most common cause of complaint (63\%) was the adverse effects, of which the most common ones were phytotherapy (45.2\%) and then cupping

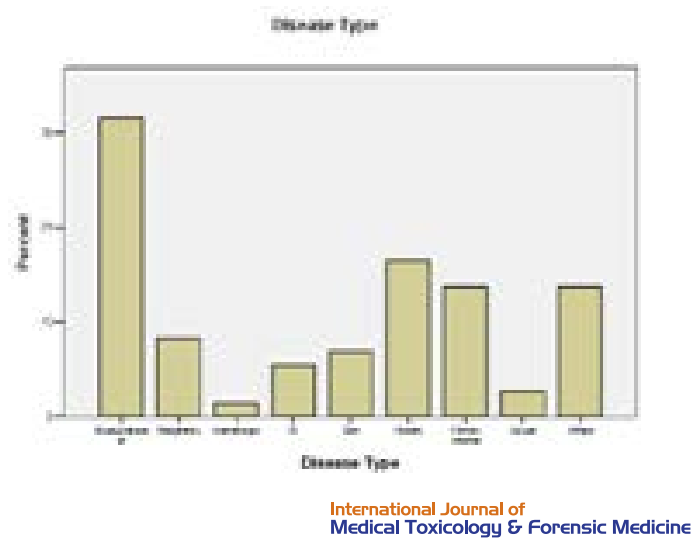

Figure 2. Type of disease among patients

Others: The others included weakness, addiction, varicose veins, and peripheral nervous system disorders.

Type of malignancy: Breast and lung cancer were the most frequent, each $33.3 \%$, followed by uterus and blood cancer.

Chronic internal disease: Diabetes mellitus, Hypertension, etc.
(20.5\%). The error significantly differed between physician and non-physician healers. The error may be a lack of caution or medical error and is due to mistakes in programming and performance, leading to unwanted outcomes $[7,8]$. The legal issues in different countries vary, and some normal cases may be considered as a medical error in other countries $[9,10]$. This matter would lead to some shortcomings in comparisons between different settings [11]. The factor analysis for errors would help determine a definite cause of errors and faults and to program better and reduce the rate of errors, including human, technical, and organizational ones [12-14].

In a local study, $60 \%$ of subjects reported in Tehran use at least one complementary and traditional method [1]. Also, $53.3 \%$ of general physicians have used these methods during their previous year of practice [2]. The use of complementary medicine for post-trauma medications is reported in $4.1 \%$ of patients [15]. Mahmoudian et al. assessed 256 cases attending a center for Iranian traditional medicine in Isfahan City, Iran, with a mean age of 38 years, and nearly one-third of cases were female [5].

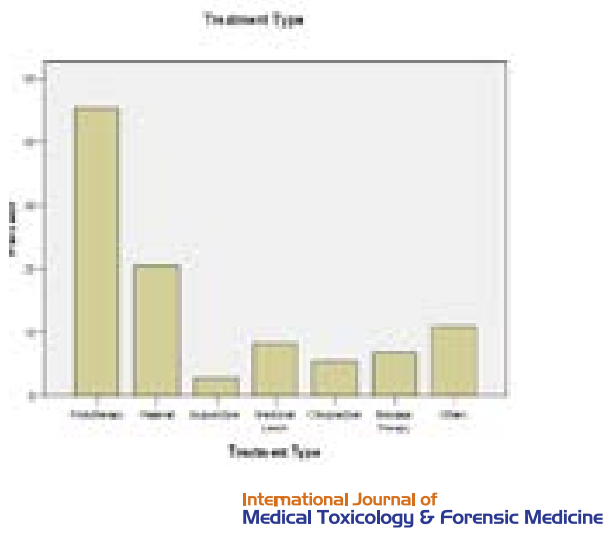

Figure 3. Treatment type 
In Tehran, another study reported the mean age of 32 years and $57 \%$ females for users of complementary medicine [5]. Among patients attending as the outpatients to general practitioners, the mean age of clients was 40 years, and 55\% were female [2]. The mean age in our study was 39 years with the same male and female percentage. As seen, the mean age in our study was similar to other studies. In a study among Asian Americans, the majority of them were using complementary medicine for low back pain [16]. Also, Korean traditional medicine is frequently used in Korea [17]. In a study in Isfahan, Iran, the most common cause of using traditional medicine was low back pain, and most cure rates $(50 \%)$ were for weight reduction. In a study in three Iranian cities, the most common cause of seeking traditional medicine was musculoskeletal problems [2]. It was also the most common cause in Tehran, and the next common cause was mental problems [1]. In our study, musculoskeletal complaints were the most common ones.

Incidental contamination of herbal medications should be considered. Contamination with chemical drugs such as corticosteroids, heavy metals, pesticides, or microorganisms has been reported in China and India [18, 19]. In our study, it was established that some herbal drugs were intentionally contaminated with corticosteroids and substances such as opium and stimulants leading to life-threatening adverse effects. Those complications included femoral head avascular necrosis (two cases due to weight reduction drugs mixed with corticosteroids) and death (in one case due to methadone addition for pain reduction). Also, there were two asymptomatic cases with amphetamines contamination of herbal medication for weight reduction. In a study about problems of traditional and complementary medicine, some debates were considered, including lack of scientific evidence about the efficacy of existing agents, no instructions and guideline for use, lack of care centers and also legal associations for complaints, and unrecognized status of the therapists [3].

For this reason, the complainees in our study ranged from the traditional healers to specialist physicians. This matter shows the need to define rules for presenting centers of traditional medicine with sufficient training to be accepted in societies. This matter would result in a lower rate of complaints from patients about traditional medicine. Also, our study demonstrated that being a physician would result significantly differed fault, or on the other word, punishment either legal or non-legal one for the healers and for this matter, further acknowledgments among non-physicians should be considered as a preventive approach to reduce the burden of problems. Besides, additional focus in public media to use traditional medicine would result in a significant reduction in the problem.

This study showed some differences with Ghaed et al. results that reported the most common reason for the use of complementary alternative medicine was the common cold in one-third of cases [20]. Similarly, Sheikhrabori et al. showed that the most common therapeutic options were medicinal plants used by $85 \%$ of the participants [21]. Dastgheib et al. reported that patients with alopecia and acne significantly utilized more alternative and complementary medicine [22]. But our study showed different patterns, and it may be due to cultural differences. Among the participants in the study by Abolhassani et al., $98 \%$ had previous conventional medicine history due to some chronic diseases [23]. But this rate was lower in our study. Some differences between studies are due to various methods used and different studied disorders as well as the knowledge level in this era among Iranian patients [24-36].

\section{Conclusion}

Based on this study, the adverse effects were the main problem of complementary and alternative therapies that were confirmed in more than half of the complaints. The proof of malpractice had a significant relationship with the age and work experience of the therapists and the work field, including physicians or non-physicians. However, further studies with multi-center sampling and larger sample sizes are required to gain more evidencebased information and systematic programming to reduce complaints and problems in traditional medicine therapy.

\section{Ethical Considerations}

\section{Compliance with ethical guidelines}

Patients' personal information will be confidential in this research. The ethical code for this was IR.SBMU. MSP.REC.1396.117 from Shahid Beheshti University of Medical Sciences.

\section{Funding}

This research did not receive any specific grant from funding agencies in the public, commercial, or not-forprofit sectors.

\section{Author's contributions}

Study design and writing article: Mohamad ali Emam Hadi, Baharak Sabet Divshaly; Supervision: Mohamad 
ali Emam Hadi, Farahnaz Azimy; Implementation, data analysis: Baharak Sabet Divshaly, Babak Sabet Divshaly.

\section{Conflict of interest}

The authors declared no conflict of interest.

\section{Acknowledgements}

Authors are grateful to the Forensic Medicine Organization for providing access to the complaints information.

\section{References}

[1] Tehrani-Banihashemi SA, Asgharifard H, Haghdoust AA, Barghamadi M, Mohammad-Hosseini N. [The use of complementary/alternative medicine among the general population in Tehran, Iran (Persian)]. Payesh J. 2008; 7(4):355-62. https:// www.sid.ir/En/Journal/ViewPaper.aspx?ID=117989

[2] Behnood-Rod A, Afzali Poor Khoshkbejari M, Pourzargar P Hassanzadeh M, Moharamzad Y, Foroughi F. Complementary and alternative medicine use among Iranian patients attending urban outpatient general practices. Complement Ther Clin Pract. 2018; 30:58-63. [DOI:10.1016/j.ctcp.2017.12.008] [PMID]

[3] Taghipour A, Bahrami Taghanaky H, Hoseinzade H, Noras MR. Ethical and legal challenges in Complementary and alternative medicine. Iranian Journal of Medical Ethics and History of Medicine. 2016; 9(3):23-31. Available from: https:// www.sid.ir/en/journal/ViewPaper.aspx?ID=547206

[4] Montross-Thomas LP, Meier EA, Reynolds-Norolahi K, Raskin EE, Slater D, Mills PJ, et al. Inpatients' preferences, beliefs, and stated willingness to pay for complementary and alternative medicine treatments. J Altern complement med. 2017; 23(4):259-63. [DOI:10.1089/acm.2016.0288] [PMID]

[5] Mahmoudian A, Golshiri P, Rezaei G, Akbari M. Patients' satisfaction form Iranian traditional medicine. Journal of Isfahan Medical School. 2012; (30):1550-8. Available from: file:///C:/ Users/Negah-R-04/Downloads/2221-10182-2-PB.pdf

[6] Harpwood V. Guidelines in medical practice: The legal issues. Cephalalgia. 1998; 21(Suppl. 18):56-62. [DOI:10.1177/03 33102498018S2114] [PMID]

[7] Mohammadynejad Toolarood H. Islamic Penal Code.Tehran: Akhavan Publication; 2014.

[8] Kelly DC, Manguno-Mire G. Commentary: Helling v. carey, caveat medicus. J Am Acad Psychiatry Law. 2008; 36(3):306-9. [PMID]

[9] Maksymovicz K, Jurek T, Trubner K. [Regulations of forensic medicine specialists employed as legal experts in Germany and in Poland (Polish)]. Arch Med Sadowej Kryminol. 2005; 55(2):157-61. [PMID]

[10] Roscam Abbing HD. [Practice guidelines for medical treatment from the perspective of health law (Dutch)]. Ned Tijdschr Geneeskd. 1998; 142(45):2480-4. [PMID]
[11] Lee JS, Choe JH, Lee HS, Seo JT. Urologic complications following obstetric and gynecologic surgery. Korean J Urol. 2012 53(11):795-9. [DOI:10.4111/kju.2012.53.11.795] [PMID] [PMCID]

[12] Dolinak D, Matshes E, Lew E. Forensic pathology: Principles and practice. Burlington, Mass: Elsevier Academic Press; 2005.

[13] Zakersalehi G. [Study on the Legal Status of Traditional and Complementary Medicine and the Challenges Ahead in Iran (Persian)]. Iran J Med Law. 2017; 10(39):101-20. Available from: http://ijmedicallaw.ir/article-1-656-en.pdf

[14] WHO Health Organization. WHO Traditional Medicine Strategy 2002-2005. Geneva: WHO Publication; 2002. http:// www.beovita.eu/pdf/WHO_EDM_TRM_2004.pdf

[15] Kalantarmotamedi MH, Aboui A, Hafezi-Nejad N, Saadat S, Rahimi-movaghar A, Motevalian A et al. Prevalence and costs of complementary and alternative medicine among traumatic patients in Iran. Iranian J Public Health. 2018; 47(10):1558-66. [PMID]

[16] Mehta DH, Davis RB, MacCarthy EP. Use of complementary and alternative therapies by Asian Americans. Results from the National Health Interview Survey. J Gen Intern Med. 2007; 22(6):762-7. [DOI:10.1007/s11606-007-0166-8] [PMID] [PMCID]

[17] Oh IH, Yoon S-J, Park M, An S. Disease-specific differences in use of traditional Korean medicine in Korea. BMC Complement Altern Med. 2015; 15:141. [DOI:10.1186/s12906-0150657-9] [PMID] [PMCID]

[18] Ekor M. The growing use of herbal medicines: Issues relating to adverse reactions and challenges in monitoring safety. Front Pharmacol. 2013; 4:177. [DOI:10.3389/fphar.2013.00177] [PMID] [PMCID]

[19] Barnes J. Quality, efficacy and safety of complementary medicines: Fashions, facts and future. Part I Regulation and quality. Br J Clin Pharmacol. 2003; 55(3):226-33. [DOI:10.1046/ j.1365-2125.2003.01810.x] [PMID] [PMCID]

[20] Ghaedi F, Dehghan M, Salari M, Sheikhrabori A. Complementary and alternative medicines: Usage and its determinant factors among outpatients in southeast of Iran. J Evid Based Complementary Altern Med. 2017; 22(2):210-5. [DOI:10.1177/2156587215621462] [PMID] [PMCID]

[21] Sheikhrabori A, Dehghan M, Ghaedi F, Khademi GR Complementary and alternative medicine usage and its determinant factors among diabetic patients: An Iranian case. J Evid Based Complementary Altern Med. 2017; 22(3):449-54. [DOI:10.1177/2156587216675079] [PMID] [PMCID]

[22] Dastgheib L, Farahangiz S, Adelpour Z, Salehi A. The prevalence of complementary and alternative medicine use among dermatology outpatients in Shiraz, Iran. J Evid Based Complementary Altern Med. 2017; 22(4):731-5. [DOI:10.1177/2156587217705054] [PMID] [PMCID]

[23] Abolhassani H, Naseri M, Mahmoudzadeh S. A survey of complementary and alternative medicine in Iran. Chin J Integr Med. 2012; 18(6):409-16. [DOI:10.1007/s11655-012 1124-9] [PMID]

[24] Sadeghi M, Rabiepoor S, Forough AS, Jabbari S, Shahabi S. A Survey of medical students' knowledge and attitudes toward complementary and alternative medicine in $\mathrm{Ur}$ mia, Iran. J Evid Based Complementary Altern Med. 2016; 21(4):306-10. [DOI:10.1177/2156587215605751] [PMID] 
[25] Anbari K, Gholami M. evaluation of trends in the use of complementary and alternative medicine in health centers in Khorramabad (West of Iran). Glob J Health Sci. 2015; 8(2):726. [DOI:10.5539/gihs.v8n2p72] [PMID] [PMCID]

[26] Hashempur MH, Heydari M, Mosavat SH, Heydari ST, Shams M. Complementary and alternative medicine use in Iranian patients with diabetes mellitus. J Integr Med. 2015; 13(5):319-25. [DOI:10.1016/S2095-4964(15)60196-0]

[27] Mahmoudi GA, Almasi V, Lorzadeh N, Khansari A. The reasons for using and not using alternative medicine in Khorramabad women, west of Iran. J Pak Med Assoc. 2015; 65(6):623-5. https://www.ncbi.nlm.nih.gov/pubmed/26060159

[28] Hejazi ZA, Namjooyan F, Khanifar M. Complementary and alternative medicine for osteoporosis. Iran J Med Sci. 2016; 41(Suppl. 3):S27. https://www.ncbi.nlm.nih.gov/ pmc/articles/PMC5103533/

[29] Barikani A, Beheshti A, Javadi M, Yasi M. Knowledge, attitude and practice of general practitioners toward complementary and alternative medicine: A cross-sectional study. Acta Med Iran. 2015; 53(8):501-6. https:/ / www.ncbi.nlm.nih. gov/pubmed/26545995

[30] Dehghan M, Mokhtarabadi S, Heidari FG. Complementary and alternative medicine usage and its determinant factors among Iranian infertile couples. J Complement Integr Med. 2018; 15(2). [DOI:10.1515/jcim-2017-0138] [PMID]

[31] Zafarghandi N, Pirasteh A, Khjavi K, Bateni FS. Knowledge, attitude and behaviors of people referred to health centers of Tehran about Iranian traditional medicine. J Alborz-Univ Med. 2012; 1(2): 65-70. [DOI:10.18869/acadpub.aums.1.2.65]

[32] Bordbar M, Pasalar M, Safaei S, Kamfiroozi R, Zareifar S, Zekavat $\mathrm{O}$, et al. Complementary and alternative medicine use in thalassemia patients in Shiraz, southern Iran: A crosssectional study. J Tradit Complement Med. 2017; 8(1):141-6. [DOI:10.1016/j.jtcme.2017.05.002] [PMID] [PMCID]

[33] Bordbar M, Pasalar M, Aresehiri R, Haghpanah S, Zareifar S, Amirmoezi F. A cross-sectional study of complementary and alternative medicine use in patients with coagulation disorders in Southern Iran. J Integr Med. 2017; 15(5):359-64. [DOI:10.1016/S2095-4964(17)60343-1]

[34] Ayati MH, Pourabbasi A, Namazi N, Zargaran A, Kheiry $\mathrm{Z}$, Kazemi AH, et al. The necessity for integrating traditional, complementary, and alternative medicine into medical education curricula in Iran. J Integr Med. 2019; 17(4):296-301. https://www.sciencedirect.com/science/article/abs/pii/ S2095496419300524

[35] Mosavat SH, Heydari M, Hashempur MH, Dehghani SM. Use of complementary and alternative medicine among paediatric patients with hepatogastrointestinal diseases. East Mediterr Health J. 2018; 24(10):1018-25. [DOI:10.26719/2018.24.10.1018] [PMID]

[36] Namjooyan F, Ghanavati R, Majdinasab N, Jokari S, Janbozorgi M. Uses of complementary and alternative medicine in multiple sclerosis. J Tradit Complement Med. 2014; 4(3):14552. [DOI:10.4103/2225-4110.136543] [PMID] [PMCID] 